\title{
HONORIO DE AUTÚN (1090-1152): EL EXILIO Y LA PATRIA DEL ALMA, O SOBRE LAS ARTES'
}

\author{
Traducción de César Raña Dafonte (Universidad de Santiago de Compostela) ${ }^{2}$
}

\section{PRÓLOGO [1241D]}

A Tomás que ha obtenido por suerte el honor de un nombre apostólico, adornado con los muchos dones de la Sabiduría ${ }^{3}$, Honorio que mereció vislumbrar en la gloria del Padre a aquel a quien el escéptico Tomás mereció tocar en la tierra.

Dado que con mirada atenta observas a muchos que desean con gran nostalgia la patria, $\mathrm{y}$, sin embargo, aprecias que avanzan por rutas extraviadas al desconocer el camino; me exhortas, varón óptimo, a mi, como experto en las rutas, a que les indique el camino, y les designe por escrito los caminos más adecuados: a fin de evitar que, extraviándose [1242D] del camino verdadero, se retrasen por haberse desviado y se alejen más de la patria; como en otro tiempo [los judíos] después de salir de Egipto ${ }^{4}$, y, dirigiéndose hacia la patria no sólo con pasos corporales, sino también con el corazón, anduvieron errantes por el desierto, y de ningún modo llegaron a la patria deseada. Ahora bien, yo, no me apropiaré del camino con la envidia que destruye, sino que intentaré buscar con diligencia las cosas piadosamente aconsejadas y conduciré a los que se esfuerzan por lugares que no conocen, a la patria verdadera, y abandonaré en las tinieblas del error a los celosos, a los envidiosos, a los corruptos de corazón, por ser indignos de la patria. [1243A] También tú, iluminado por el estudio, ve delante de los perezosos, empuja a los negligentes, obliga a los que no quieren: lleva con ánimo a los que quieren y no pueden por un camino placentero a la patria deseada: y rechaza a los hijos, mejor dicho, siervos de la envidia, incluso si rivalizan por seguir, y libra al justo de los perros y quita las perlas a los cerdos 5 .

Cap. 1. El exilio del hombre es la ignorancia, su patria es la sabiduría, a la que se llega por las artes liberales, como por otras tantas ciudades.

Así como el pueblo de Dios tenía el exilio en Babilonia y su patria en Jerusalén ${ }^{6}$, del mismo modo el exilio del hombre interior es la ignorancia y su patria es la sabiduría. En efec-

\footnotetext{
1 Texto original latino, en PL, 172, 1241D-1246A. Honorio, sacerdote secular y maestro en la escuela catedralicia de Autún (Borgoña), se retiró a un monasterio benedictino donde escribió sus obras. El opúsculo que recogemos es un claro ejemplo de las ansias de ilustración intelectual en el siglo XII, de los programas de los estudios, así como del estilo claro y pedagógico del autor.

2 Agradezco vivamente al distinguido Profesor Atilano Domínguez su generosa colaboración en esta traducción.

3 No pude identificar a la persona llamada Tomás, a quien dedica el Opúsculo. En todo caso se trata de alguien muy conocido de Honorio, de gran relieve en la época. Incuso le dedica otro opúsculo: Libelus XII Quaestionum.

4 Éxodo, Caps. 5 y 6.

5 Mat. 7,6.

6 Salmo 136, 1-6
}

Revista Española de Filosofia Medieval, 17 (2010), ISNN: 1133-0902, pp. 171-179 
to, los que se instalan en la ignorancia son como moradores de una región oscura, por lo que se llaman hijos de las tinieblas (I Tes. 5,5). Por el contrario los que abrazan la sabiduría son como moradores de una región brillante, y por ello se llaman hijos de la luz (I Tes. Loc. cit.). [1243B] El camino desde este exilio hacia la patria es la ciencia, porque la ciencia versa sobre la naturaleza, y la sabiduría, en cambio, se centra en lo divino. Este viaje no se ha de realizar con pasos corporales, sino con el empuje del corazón. En efecto, este camino conduce a la patria a quienes tienden a ella, mediante diez artes y los libros que las contienen, y, por así decirlo, a través de otras tantas ciudades y villas que las sirven. Este número diez es muy simbólico. Pues, por una parte, la ley divina consta de diez mandamientos, y, por otra, la sabiduría mundana se encierra en las diez categorías. Incluso la Iglesia se compara con diez vírgenes ${ }^{7}$; este número también se establece como base de toda numeración; asimismo, a los trabajadores de la viña ${ }^{8}$ se les promete un denario.

\section{Cap. 2. La Gramática es la primera ciudad.}

[1243C] Así, pues, la primera ciudad es la gramática, mediante la cual se ha de buscar la patria: su puerta es un vocablo de cuatro sílabas, en ella el camino es una letra tripartita: la cual conduce a los habitáculos de las frases con vocales, semivocales y mudas. Ciertamente las sílabas alargadas o abreviadas de las frases son como las puertas de las casas: esta ciudad se distribuye en ocho partes, como otros tantos barrios; y este número encierra tanto la locución humana como la felicidad de las almas. En esta el nombre y el verbo ejercen el imperio como dos cónsules, el pronombre desempeña la función de procónsul, el adverbio reclama para si el lugar de prefecto: las demás partes se adaptan a otras dignidades, a las cuales se subordinan los géneros y los casos, los tiempos y otros accidentes gramaticales, como plebe sumisa. En esta ciudad Donato [1243D] y Prisciano ${ }^{9}$ enseñan una lengua nueva a los viajeros, y con unas reglas precisas conducen a los viandantes por el camino que lleva a la patria. Los feudos subordinados a esta ciudad son los libros de los poetas, que se dividen en cuatro clases, a saber, tragedias, comedias, sátira y lírica. Las tragedias son las que versan sobre guerras, como Lucano. Las comedias son las que cantan nupcias, como Terencio. Las sátiras exponen críticas, como Persio. La lírica es la que hace resonar con voz musical odas, es decir, alabanzas a los dioses o a los reyes, como Horacio.

\section{Cap. 3. La Retórica es la segunda ciudad.}

La segunda ciudad es la retórica por la cual se ha de ir a la patria: su puerta es la preocupación civil, su camino abarca tres clases de cuidados, a saber, demostrativo, deliberativo, judicial. En una parte de ella [1244A] los jefes de la Iglesia componen los Decretos, en otra los reyes y jueces proponen los edictos. Allí se promulgan las decisiones sinodales, aquí se tratan los derechos forenses. En esta ciudad Tulio [Cicerón] instruye a los caminantes para hablar con elegancia, y resume las costumbres en cuatro virtudes, a saber, prudencia, fortaleza, justicia, templanza. A esta ciudad están subordinados los relatos, las fábulas, y los libros elaborados con fin oratorio y ético, mediante los cuales se han de encaminar hacia la patria los pasos de la mente.

7 Cfr. Mat. 25,1

8 Mat. 20,2. Denarius moneda romana, se deriva de deni (diez): moneda de plata de diez «ases» (etimología de «dinero»). [El sistema de numeración decimal es el más usado, tiene como base el número diez, o sea, posee 10 dígitos (del latín digitus $=$ dedo) (o símbolos) diferentes $(0,1,2,3,4,5,6,7,8,9)$. El sistema de numeración decimal fue desarrollado por los hindúes, los árabes lo introducen en Europa, donde recibe el nombre de numeración decimal, o arábigo].

9 Los textos de los gramáticos latinos Donato y Prisciano fueron fundamentales para los medievales, especialmente para los maestros del siglo XII. 


\section{Cap. 4. La Dialéctica es la tercera ciudad.}

La tercera ciudad es la dialéctica, fortificada con muchas murallas de problemas, mediante la cual se halla el camino que lleva a los pórticos de la patria. Esta ciudad recibe a los visitantes por cinco puertas, a saber, el género, la especie, la diferencia, el propio y el accidente; de ahí que las isagoges se denominen también introducciones [1244B], porque a través de ellas se hace entrar a los que vuelven a su patria. El alcázar de esta ciudad es la sustancia, las torres circundantes son los nueve accidentes. En ella hay dos púgiles, que dividen a los luchadores con una razón firme: en efecto, el silogismo categórico e hipotético protegen a los viandantes con un armamento excelente. A los luchadores los recibe Aristóteles en los Tópicos, y los instruye con argumentos racionales, y en el Peri hermeneias los lleva al amplio campo de los silogismos ${ }^{10}$. En esta ciudad se instruyen los caminantes para luchar con las armas de la razón contra los herejes y otros enemigos, que se esfuerzan por oponérseles en su camino, como en otro tiempo se opuso Amelec al pueblo de Dios ${ }^{11}$.

\section{Cap. 5. La Aritmética es la cuarta ciudad.}

La aritmética es la cuarta ciudad por la que se ha de intentar alcanzar la patria. En ella, según enseña Boecio, el número par e impar se combinan de múltiples maneras. La Criba ${ }^{12}$ [1244C] con su actividad selecciona los números primos mediante los números compuestos; el Ábaco ${ }^{13}$ mediante los dedos y articulaciones multiplica avanzando, regresando divide, y mediante partículas convierte la unidad en mil partes. Con esta lucha de ritmos provoca la oposición de números pares e impares, la suerte ordena de un modo determinado a los «Escachos» ${ }^{14}$ para el certamen, y la tabla senaria los junta de modo fortuito después de arrojar los dados. En la escuela de esta ciudad el caminante aprende que Dios dispuso todas las cosas con medida, número y peso $^{15}$.

Cap. 6. La Música es la quinta ciudad para los que prosiguen su camino hacia la sabiduría.

La quinta ciudad es la música, mediante la cual se pasa a los cantos de la patria. En esta ciudad, según la enseñanza de Boecio, el coro, de una parte con voces graves de varón y de otra parte con voces agudas de niños, [1244D] da muestras de júbilo a Dios: los órganos con los tubos, las cítaras con las cuerdas resuenan, y los címbalos retiñen con la percusión; siete voces disonantes producen una apropiada armonía. La triple modulación que se realiza mediante el viento, el tacto y el pulso, proporciona a las siete armonías del senario la dignidad, que contiene el conjunto: a la vez que con los intervalos y las proporciones de los tonos produce una dulce melodía. En esta ciudad se enseña a los caminantes a pasar de la ordenación de las costumbres al concierto de los cielos.

\footnotetext{
10 Son claras las alusiones a la Isagoge de Porfirio, y a obras lógicas de Aristóteles (Logica vetus).

11 Éxodo, 17, 8-16.

12 La Criba de Eratóstenes (Matemático griego del siglo III a. C.) es un algoritmo, un procedimiento, para determinar todos los números primos hasta cierto número natural dado.

13 Ábaco: instrumento que sirve para facilitar cálculos sencillos y operaciones matemáticas. Su origen se remonta a muchos años antes de nuestra era.

14 No conseguí identificar la posible traducción de «Scachos», pero en todo caso es algo que se refiere a un recurso de enseñanza de las matemáticas.

15 Sabiduría, 11, 20.
} 


\section{Cap. 7. La Geometría es la sexta ciudad.}

La sexta ciudad es la geometría, por la que se busca la patria. En ella Arato ${ }^{16}$ explica el mapa del mundo, en el que sitúa a Asia, África y Europa; enumera los montes, las ciudades y los ríos de toda la superficie de la tierra, por los cuales recuerda que pasan los caminantes.

\section{Cap. 8. La Astronomía es la séptima ciudad [1245A].}

La séptima ciudad, que conduce a las moradas de la patria, es la astronomía. En ella Higino $^{17}$ mediante el Astrolabio ${ }^{18}$ despliega la esfera celeste, y pone de manifiesto la luna creciente y menguante, sus fases, y los avances y retrocesos de los planetas del sol. En la esfera celeste dibuja los signos del zodíaco y los restantes prodigios de la bóveda celeste, a través de las lejanas estrellas. En esta disciplina Julio ${ }^{19}$ explica el cálculo por el cual enumera los años del siglo, a través de la serie de los reyes. Según ella los círculos celestes se mueven suavemente con su choque, e incitan a los caminantes a alabar al Creador.

\section{Cap. 9. La Física es la octava ciudad.}

La física [medicina] es la octava ciudad, a través de la cual se busca la patria. En ella Hipócrates enseña a los viajeros el poder y la naturaleza de las hierbas, de las plantas, de las piedras, de los animales; y [1245B], mediante la curación de los cuerpos, conduce a la curación de las almas.

\section{Cap. 10. La Mecánica es la novena ciudad.}

La mecánica es la novena ciudad por la cual se ha de buscar la patria. Esta enseña a los caminantes todas las formas de trabajar los metales, la madera, el mármol; además enseña la pintura, la escultura, y todas las artes que se ejercen con las manos. Esta disciplina erigió la torre de Nemrod ${ }^{20}$, construyó el templo de Salomón ${ }^{21}$. Ella construyó el Arca de Noé22, y todas las fortificaciones del orbe; y descubrió los diversos tejidos de los vestidos.

\section{Cap. 11. La Economía es la décima ciudad.}

La economía es la décima ciudad por la que nos acercamos a los atrios de la patria. Ella ordena los reinos y los honores, [1245C] ella distingue los deberes y los rangos sociales. También enseña, a los que se apresuran hacia la patria, que los hombres se unen a los coros de los ángeles según el grado de sus méritos.

16 Aratos: Poeta griego del siglo III a. C. Escribió un poema didáctico: Los fenómenos, traducido del griego al latín por Cicerón. En él ofrece los conocimientos cosmológicos de su tiempo.

17 Caius Iulius Hyginus: de origen Hispano, Siglo I d. C. Obras: Fabulae, De astronomia (es probable que ambas obras correspondan a este autor)

18 Astrolabio: Instrumento que se utilizaba para observar la posición de los astros. Los antiguos atribuían su invención al astrónomo griego Hiparco (S. II a. C.).

19 Se refiere a Julio César como reformador del Calendario en el año 46 a. de C.

20 Génesis, Caps. 10, 11.

21 I Reyes, Cap. 6.

22 Génesis, 6, 14-16. 
Cap. 12. Una vez cursadas las Artes Liberales se llega a la patria, o verdadera sabiduria, que reluce en las Sagradas Escrituras, y que alcanza su perfección en la visión de Dios.

Una vez recorridas estas artes, a modo de ciudades, se llega a la Sagrada Escritura como a la patria verdadera, en la que reina una múltiple sabiduría ${ }^{23}$. El que construye la casa con la Escritura la fortifica con los siete dones del Espíritu Santo, como con siete columnas (Prov. 9,1): la edifica sólidamente con cuatro paredes, valiéndose de la cuádruple interpretación o sentido, a saber, histórico, alegórico, tropológico, y anagógico. La historia se refiere a los hechos realizados: como que Jerusalén fue la ciudad de los judíos, en la que estaba el templo del Señor. [1245D] La alegoría existe cuando se dice una cosa, y se significa otra: como que Jerusalén es la Iglesia, y nosotros mismos templo del Señor (II Cor. 6,16). La tropología es la moralidad: como que Jerusalén es cualquier alma fiel, y en la que el templo es el corazón limpio, y el Espíritu Santo es su habitante. La anagogía es el sentido superior, que nos lleva a Dios, y al siglo futuro: como que Jerusalén es la ciudad celeste, en la que los santos, unidos a los ángeles, tendrán presente a Dios (Apoc. 21,2). En esta casa la sabiduría prepara un banquete a los que allí llegan, y los sacia con variados y deliciosos manjares. Finalmente la sabiduría introducirá en la Jerusalén celeste, en la que se contemplará al Rey de la gloria en todo su esplendor, y cuya hermosura admiran el sol y la luna. En ella los nueve órdenes de los ángeles [1246A] no cesan de alabar al Rey de reyes, al cual desean insaciablemente contemplar. En esta patria los patriarcas prefiguran a Cristo, los profetas lo anuncian con los escritos, los apóstoles lo predican al mundo con prodigios y virtudes, los mártires le inmolan su sangre, y las vírgenes lo adoran ofreciendo su castidad. También en esta patria los estudiosos suben al monte de la contemplación, en el cual ven a Cristo entre Moisés y Elías, con un vestido blanco como la nieve, radiante como el sol ${ }^{24}$ : pues ellos, mediante la Sagrada Escritura y las criaturas visibles, que son sus vestigios, entienden que Él es juez de vivos y muertos, consustancial con el Padre ${ }^{25}$.

Cap. 13. Dios será visto por los santos según las virtudes de cada uno.

[1246B] Ahora corresponde reflexionar sobre la contemplación de las realidades celestes: en efecto, una vez abandonado el hombre carnal, corresponde contemplar cara a cara esas realidades, y gozar de ellas en el reino celestial. En él hay muchas mansiones ${ }^{26}$, es decir, múltiples modos de manifestación divina, según los cuales los santos verán al Dios de dioses en Sión, es decir, en la contemplación divina, cuando progresen de virtud en virtud, por ejemplo: los buenos verán a Dios según el grado de bondad; los justos, según el grado de justicia; los sabios, según el grado de sabiduría; los pacíficos, según el grado de paz (Mat. 5,1-10); y todos los demás lo verán según las distintas e innumerables virtudes.

Cap. 14. Dios no puede ser comprendido por nadie, a no ser por si mismo. La visión de Dios reconfortará eternamente a los bienaventurados; el recuerdo de los pecados cometidos atormentará sin fin a los malvados. [1246C]

Dado, pues, que supera todo entendimiento, a Dios nadie lo ha visto nunca, ni nunca lo verá: «Porque nadie conoció al Padre, a no ser el Hijo, ni nadie conoció al Hijo, sino sólo el Padre solo» (Mat. 11,27). Porque todo lo que acerca de Dios se mostró a los antiguos, se llama

23 Como es notorio, el saber basado en la Biblia (Scientia Fidei) durante la Edad Media era el saber supremo, precisamente en el siglo XII comenzó a denominarse Teología, con Pedro Abelardo.

24 Mat. 17, 2-3.

25 Rom. 1, 20; San Agustín, Enarratines in Psalmos, PL, 36, 518; Juan Escoto Eriúgena, Homilia in Prologum S. Evangelii secundum Johannem, PL; 122, 289C.

26 Juan, 14, 2.

Revista Española de Filosofia Medieval, 17 (2010), ISNN: 1133-0902, pp. 171-179 
Dios; así se dice de Jacob: «He visto a Dios cara a cara» (Gén. 32,30). Y en otro lugar, también de Moisés: «Moisés conversaba con Dios cara a cara como con un amigo» (Éxodo 33,11). Y también el profeta: «He visto al Señor sentado sobre un trono sublime», etc. (Isa. 6,1). En cambio, los limpios de corazón verán a Dios en Sión en el futuro, es decir, en la contemplación divina, en cuanto que aparecerá a cada uno [1246D], cuando se manifestará a los que lo aman, porque cada uno en sí mismo y en toda criatura verá a Dios, según su medida, cuando Dios será todo en todas las cosas. Los que llegan a esta patria, verán de este modo al Rey de la gloria en su esplendor, el cual será su gozo, como la luz para los ojos. Pero, aquellos que, apegados a las cosas perecederas, permanezcan en el exilio, soportarán las tinieblas exteriores, y, como ojos dañados, jamás percibirán la luz eterna. Por el contrario estos tendrán presentes las variadas y múltiples fantasías de los vicios, como a fieras salvajes, de las que quieren constantemente huir, pero no pueden conseguirlo; porque unas después de otras siempre se les interponen, y los sumergen en un inmenso abismo de tristeza y desesperación. Ejercítate en estos temas, y enséñalos a otros: para que evites estas cosas y consigas aquellas. Amén.

\title{
TEXTO LATINO
}

\author{
Honorius Augustodunensis (1090?-1152): \\ De animae exsilio et patria, alias, De artibus (PL, 172, 1241D-1246A)
}

\section{PROLOGUS. [1241D]}

Thomae gratiam apostolici nominis sortito, multis donis Sophiae insignito Honorius illum in gloria Patris cernere, quem Thomas dubitans meruit in terris tangere. Quia vigilanti oculo plerosque conspicis patriam magnopere desiderare, sed, utpote viae ignaros per devia properare; hortaris me, optime virorum, quasi peritum locorum his viam demonstrare, ac viciniora loca stylo designare: ne forte longius a via [1242D] aberrantes regia, in devio retardentur, et magis a patria elongentur; ut quondam de Aegypto egressi, ad patriam tendentes non modo corpore, sed corde, longo tempore in eremo erraverunt, et minime ad optabilem patriam pervenerunt. Ego autem cum invidia tabescente iter non habebo, pie injuncta impigre exsequi tentabo, quosque studiosos per ignota loca ad notam patriam deducam, invidos, lividos, corde tabidos, patria immeritos in tenebris erroris derelinquam. Tu [1243A] quoque, studio florens, ignavos praecede, et negligentes move, nolentes coge: volentes sed non valentes per delectabile iter ad jucundam patriam trahe: filios imo servos invidiae, etiam sequi certantes repelle, et sanctum canibus, gemmas porcis tolle.

CAP. I. Exsilium hominis ignorantia; patria est sapientia, ad quam per artes liberales, veluti per totidem civitates pervenitur.

Sicut populo Dei exsilium erat in Babylonia, Jerusalem vero patria, sic interioris hominis exsilium est ignorantia, patria autem sapientia. In ignorantia quippe positi quasi in tenebrosa regione commorantur, unde et filii tenebrarum (I Thess. V) cognominantur. In sapientia autem locati quasi in lucida regione conversantur, ideo et filii lucis (ibid.) appellantur. [1243B] De hoc exsilio ad patriam via est scientia, scientia enim in rebus physicis: sapientia vero consideratur in divinis. Per hanc viam gradiendum est non passibus corporis, sed affectibus cordis. Haec quippe via ducit ad patriam tendentes per decem artes, et libros sibi adhaerentes, et quasi per 
totidem civitates et villas sibi servientes. Qui numerus multis sacramentis est involutus. Nam et divina lex decem praeceptis comprehenditur: et saecularis sapientia decem categoriis includitur. Sed et tota Ecclesia decem virginibus comparatur; quia hic numerus limes omnium multiplicium numerorum ponitur: unde et in vinea laborantibus denarius repromittitur.

CAP. II. De prima civitate, grammatica.

[1243C] Prima itaque civitas est grammatica, per quam petenda est patria: hujus porta est vox quadrifida, per quam iter est littera tripartita: quae vocalibus, semi vocalibus, mutis, ducit ad sententiarum habitacula. Porro syllabae productae vel correptae dictionum, sunt quasi quaedam ostia domorum: haec urbs in octo partes quasi in totidem regiones distribuitur, qui numerus et humanam locutionem et animarum beatitudines complectitur. In hac nomen et verbum quasi duo consules imperant, pronomen locum proconsulis, adverbium locum praefecti sibi vendicant: aliae partes aliis dignitatibus coaptantur, quibus genera et casus, tempora et aliae species quasi plebes subjectae famulantur. In hac urbe Donatus [1243D] et Priscianus docent novam linguam viantes, et certis regulis deducunt per viam ad patriam ambulantes. Villae, huic subditae, sunt libri poetarum, qui in quatuor species dividuntur, scilicet in tragoedias, in comoedias, in satyrica, in lyrica. Tragoediae sunt quae bella tractant, ut Lucanus. Comaediae sunt, quae nuptialia cantant, ut Terentius. Satyrae, quae reprehensiva scribunt, ut Persius. Lyrica, quae odas, id est laudes deorum vel regum hymnilega voce resonant, ut Horatius.

CAP. III. De rhetorica, altera civitate.

Secunda civitas est rhetorica, per quam adeunda est patria: hujus porta est civilis cura, iter vero tripartitum genus curarum, videlicet demonstrativum, deliberativum, judiciale. In una parte hujus [1244A] civitatis praesules Ecclesiae Decreta componunt, in altera reges et judices edicta proponunt. Hinc synodalia promulgantur, inde forensia jura tractantur. In hac urbe Tullius itinerantes ornate loqui instruit, quatuor virtutibus scilicet prudentia, fortitudine, justitia, temperantia mores componit. Huic urbi subjacent historiae, fabulae, libri oratorie et ethico conscripti, per quos gressus mentis ad patriam sunt dirigendi.

CAP. IV.Dialectica, tertia civitas.

Tertia civitas est dialectica, multis quaestionum propugnaculis munita, per quam iter est ad patriae atria. Haec per quinque portas adventantes recipit, scilicet per genus, per species, per differens, per proprium, per accidens; unde et isagogae introductiones [1244B] dicuntur, quia per has repatriantes introducuntur. Arx hujus urbis est substantia; turres circumstantes novem sunt accidentia. In hac duo pugiles sunt et litigantes certa ratione dirimunt: cathegorico et hypothetico syllogismo quasi praeclaris armis viantes muniunt. Quos Aristoteles in topica recipit, argumentis instruit, in perihermeniis ad latum campum syllogismorum educit. In hac urbe docentur itinerantes haereticis, et aliis hostibus armis rationis resistere, qui eis, ut olim Amalec populo Dei, in hac via moliuntur obsistere.

CAP. V. Quarta civitas arithmetica.

Quarta civitas est arithmetica, per quam quaerenda est patria. In hac, Boetio docente, par et impar numerus multipliciter se complicant. Cribrum [1244C] simplices numeros per multiplices numeros reciprocat; Habacus per digitos, et articulos eundo multiplicat, redeundo dividit, minutiis monadem in mille particulas redigit. In hac rhythmimachia pares et impares numeros in pugnam provocat, alea Scachos certo numero in certamen ordinat, tabula jactis tesseris senaria sorte congregat. In hujus urbis schola viator discit, quod Deus omnia in mensura et numero et pondere disposuit.

Revista Española de Filosofia Medieval, 17 (2010), ISNN: 1133-0902, pp. 171-179 
CAP. VI. Quinta civitas pergentium ad sapientiam musica.

Quinta civitas est musica, per quam transitus est ad patriae cantica. In hac urbe per Boetii doctrinam hinc chorus viris gravibus, inde puerilis acutis [1244D] vocibus Deo jubilat: organa fistulis, citharae fidibus concrepant, cymbala pulsu tinniunt; septem dissonae voces consonam harmoniae efficiunt. Triplex modulatio, quae fit flatu, tactu, pulsu, septem consonantiis senarii dignitatem, universitatem continentem, concinit: dum intervallis et proportionibus tonorum dulce melos reddit. In hac urbe docentur viantes per modulamen morum transire ad concentum coelorum.

\section{CAP. VII. Civitas sexta geometria.}

Sexta civitas est geometria, per quam inquiritur patria. In hac Aratus mappam mundi expandit, in qua Asiam, Africam, Europam ostendit; montes, urbes, flumina totius orbis enumerat, per quae itinerantes transire commemorat.

CAP. VIII. De astronomia, civitate septima. [1245A]

Septima civitas astronomia, quae deducit ad patriae habitacula. In hac Hyginus per astrolabium incrementa ac decrementa lunae, anfractus, solis planetarum cursus ac recursus ostendit, sphaeram evolvit: in qua signa zodiaci ac caetera monstra coeli per distantes stellas depingit. In hac Julius computum explicat, per quem annos saeculi per seriem regum enumerat. In hac orbes coelestes collisione sua dulciter persultant, atque viantes ad laudem Conditoris incitant.

CAP. IX. Physica, civitas octava.

Octava civitas est physica per quam petitur patria. In hac docet Hippocrates viatores vires et naturas herbarum, arborum, lapidum, animalium; et [1245B] per medelam corporum deducit ad medelam animarum.

\section{CAP. X. De mechanica, civitate nona.}

Nona civitas est mechanica, per quam subeunda est patria, haec doces [docet] viantes omne opus metallorum, lignorum, marmorum, insuper picturas, sculpturas, et omnes artes, quae manibus fiunt. Haec turrim Nemrod erexit, haec templum Salomonis construxit. Haec arcam Noe et omnia moenia totius orbis instituit, et varias texturas vestium docuit.

CAP. XI. Oeconomica, civitas decima.

Decima civitas est oeconomica, per quam pervenitur ad patriae atria. Haec disponit regna et dignitates, [1245C] haec distinguit officia et ordines. Haec docet ad patriam properantes juxta ordinem meritorum homines conjungi ordinibus angelorum.

CAP. XII. Decursis artibus liberalibus pervenitur ad patriam, seu veram sapientiam, in divinis Scripturis relucentem, et in visione Dei perfectam.

His artibus quasi civitatibus pertransitis pervenitur ad sacram Scripturam quasi ad veram patriam, in qua multiplex sapientia regnat. Quae Scriptura sibi domum aedificat, quam septem donis Spiritus sancti ut septem columnis roborat (Prov. IX) : quadripartito intellectu in quatuor parietibus copulat, scilicet historico, allegorico, tropologico, anagogico. Historia quippe est res gesta, ut: Hierusalem fuit civitas Judaeorum, in qua fuit templum Domini. [1245D] Allegoria est cum, aliud dicitur, aliud intelligitur, ut: Hierusalem est Ecclesia, nosipsi templum Domini (II Cor. VI) . Tropologia est moralitas ut: Hierusalem est anima quaeque fidelis, in qua tem- 
plum est cor mundum, habitator Spiritus sanctus. Anagoge vero est superior sensus ducens ad Deum, et ad futurum saeculum, ut: Hierusalem est superna civitas, in qua sancti angelis conjuncti Deum habebunt praesentem (Apoc. XXI) . In hac domo sapientia ad se venientibus convivium praeparat, quos variis ac deliciosis ferculis satiat. Demum in coelestem Hierusalem introducet, in qua rex gloriae in decore suo videbitur, cujus pulchritudinem sol et luna mirantur In hac novem ordinem angelorum [1246A] non cessant Regem regum laudare, in quem insatiabiliter desiderant prospicere. In hac patria Christum patriarchae figuris praesignant, prophetae scriptis praenuntiant, apostoli signis et virtutibus mundo praedicant, martyres ei sanguinem suum immolant, virgines castitatem offerentes adorant. In hac patria quoque studiosi in montem contemplationis ascendunt, in quo Christum inter Moysen et Eliam in nivea veste, ut sol, radiantem conspiciunt: quia eum judicem vivorum et mortuorum, Patri coaequalem per sacram Scripturam, et visibilem creaturam, quae sunt vestes ejus, intelligunt.

CAP. XIII. Deus a sanctis secundum singulorum virtutes videbitur.

[1246B] Talia nunc meditari est coelestia contemplari: carne vero exuta haec facie ad faciem videre, est in coelesti regno gaudere. In quo sunt multae mansiones, hoc est, multiplices divinae apparationes: in quibus sancti Deum deorum in Sion, id est in divina speculatione videbunt, quando de virtute in virtutem ibunt, verbi gratia: boni Deum, secundum hoc quod bonitas dicitur, videbunt; justi, secundum hoc quod justitia; sapientes, secundum hoc quod sapientia; pacifici, secundum hoc quod pax (Matth. V), et alii aliis virtutibus in infinitum visuri sunt.

CAP. XIV. Deus a nemine comprehendi nisi a seipso potest. Beatos Dei visio recreabit aeternum; impios patratorum scelerum recordatio sine fine torquebit. [1246C]

Secundum hoc autem, quod exsuperat omnem intellectum, Deum nemo vidit unquam, nec unquam videbit: Quia nemo novit Patrem nisi Filius, nec Filium quis novit nisi solus Pater (Matth. XI) . Quidquid enim patribus de Deo ostensum est, Deus dicitur; sicut de Jacob: Vidi Dominum facie ad faciem (Gen. XXXII) . Et iterum de Moyse: Loquebatur Moyses cum Domino facie ad faciem, quasi amicus amico (Exod. XXXIII) . Et item propheta: Vidi Dominum sedentem super solium excelsum, etc. (Isa. VI) . Mundicordes autem in futuro Deum in Sion, id est in divina speculatione videbunt, secundum quod unicuique [1246D] apparebit, quando suis dilectoribus seipsum manifestabit; quia unusquisque in seipso et in omni creatura Deum pro modulo suo videbit, quando Deus in omnibus omnia erit. Qui ad hanc patriam perveniunt, hoc modo Regem gloriae in decore suo videbunt, qui erit gaudium eorum, ut lux oculorum. Qui autem transitoriis oblectati in exsilio permanserint, exteriores tenebras subibunt, et ut saucii oculi aeternum lumen in aeternum refugiunt. Sed eis variae et multiplices vitiorum phantasiae, ut truces bestiae, occurrunt, quas semper volunt effugere, sed non valent evadere; quia aliae prae aliis semper se ingerunt, et in immensum barathrum tristitiae et desperationis demergunt. In his te exerce, haec alios doce: ut ista evadas, ad illa pervenias. Amen.

César Raña Dafonte cesar.rana@usc.es 